\title{
Sucrose incentive shifts in the Skinner box with thirsty rats
}

\author{
ALEXANDER J. ROSEN and MITCHELL JACOBS, Uni- \\ versity of Illinois at Chicago Circle, Chicago, Ill. 60680
}

Water-deprived rats $(N=4)$ presented on a test day with counterbalanced series of sucrose concentrations $115 \mathrm{~min}$ each) in a Skinner box demonstrated lower responding for a $32 \%$ solution than for 4,8 , or $16 \%$ solutions during initial exposure but higher responding for $32 \%$ during later exposures. Results are discussed in terms of an interaction of sucrose rewards with motivational state.

Guttman (1953) has reported that hungry rats, exposed in a Skinner box to changing sucrose concentrations $(4,8,16$, and $32 \%$ ) responded in a monotonically increasing fashion to the increasing concentrations. Tombaugh \& Marx (1965) reported that thirsty rats on the other hand yield a rather different function relating bar pressing and sucrose concentrations $(4,8$, 32 , and $64 \%$ ) with less response strength at 32 and $64 \%$ than at 4 or $8 \%$. The former study presented the different concentrations in counterbalanced order. The latter study, however, used either increasing or decreasing modes of presentation. Ison \& Rosen (1965) have reported that the performance of rats for sucrose rewards appears to interact somewhat with their motivational state (hunger or thirst). It was decided, therefore, to replicate the Guttman procedure using counterbalanced presentation with thirsty rats to determine the generality of the relationship between sucrose concentration and bar pressing.

\section{METHOD}

\section{Subjects and Apparatus}

The Ss were four male, albino rats of the Sprague-Dawley strain, approximately 102 days old at the start of the experiment, obtained from Holtzman suppliers, Madison, Wisconsin. The experimental test chambers were four Plexiglas cages which were $9 \times 8 \times 8$ in. with a 2 -in. $\times 1 / 2$-in. bar protruding $1 / 2$ in. into the chamber 4 in. from the top of the cage and 3 in. from the sides of the cage.

Procedure

Upon arrival Ss were marked, handled and assigned to individual cages. The Ss were maintained on ad lib Purina Chow. Water was removed from the individual cages $23 \mathrm{~h}$ before the beginning of each day of training and on the days preceeding the four experimental sessions. The Ss were magazine trained and put on a continuous reinforcement schedule with water as reinforcement for two weeks prior to the initial experimental session. Twenty-four hours before each test session four concentrations of sucrose (table sugar and water), $4 \%, 8 \%, 16 \%$, and $32 \%$, were prepared $(\mathrm{gm} / \mathrm{ml})$. Four orders of presentation of the concentrations were selected in a counterbalanced design. The orders were (a) $4 \%-16 \%-32 \%-8 \%$, (b) $8 \%-4 \%-16 \%-32 \%$, (c) $16 \%-32 \%-8 \%-4 \%$, and (d) $32 \%-8 \%-4 \%-16 \%$. On the test days the $\mathrm{S}$ was placed in the test chamber for $15 \mathrm{~min}$ and permitted to bar press for the first solution of a given order. The $S$ was then removed from the chamber and held for 5 min during which time the second solution in that order was substituted for the first and the dipper was cleaned. This procedure was carried out for the four concentrations. Each $S$ received the four orders in different sequences across the four test days. Number of reinforcements obtained in each 15 min period was recorded. Each reinforcement was approximately $.10 \mathrm{ml}$. The inter-testday interval ranged from two to seven days.

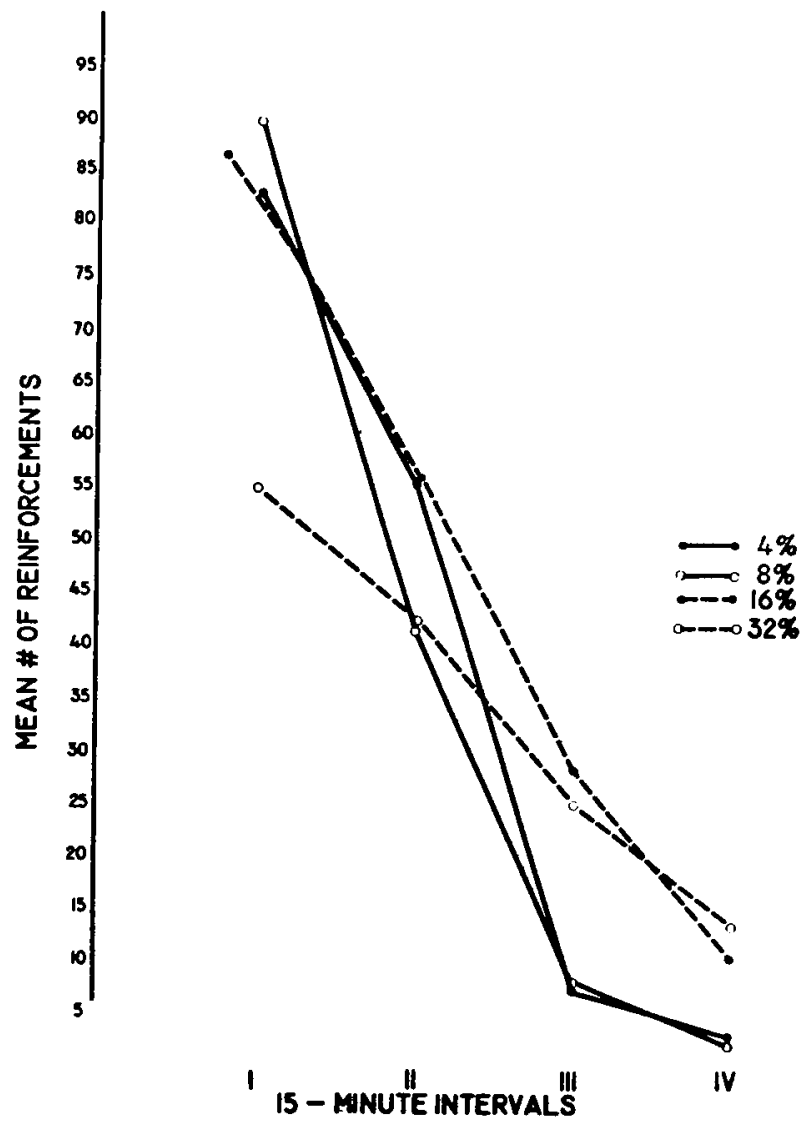

Fis. 1. Mean number of reinforcements for each of the four sucrowe concentrations as a function of auccesive $15 \mathrm{~min}$ intervals.

\section{RESULTS}

Figure 1 shows the mean number of reinforcements obtained by the Ss at each sucrose concentration over the four 15-min intervals. Analysis of variance with 15-min intervals, orders of presentation, and solutions as within-S variables demonstrated that the main effect of Intervals $(F=256.94 ; \mathrm{df}=3 / 9$ ) and the Solutions by Orders interaction $(F=20.79$; df $=9 / 27)$ were both highly significant $(p<.001)$ indicating that there was less responding for all solutions over the 1-h session independent of the order of solution presentation and that there was less of a change in responding from order to order for the $32 \%$ solution as compared to the other three solutions. During the initial $15 \mathrm{~min}$ of responding (Interval 1) the 32\% solution resulted in significantly fewer reinforcements than the other sucrose solutions $(t=7.25, \mathrm{p}<.001)$. At the third interval the $16 \%$ and the $32 \%$ solutions resulted in significantly more obtained reinforcements than the $4 \%$ and the $8 \%$ solutions $(t=2.78, p<.05)$. Although the mean number of reinforcements obtained under the $16 \%$ solution over all the intervals (44.3) was greater than the mean number under either the $4 \%$ solution $(37.1)$, the $8 \%$ solution $(35.4)$, or the $32 \%$ solution (34.8) resultant $t$ values were not large enough to attain significance $(\mathrm{p}>.05)$. 


\section{DISCUSSION}

The decline in response strength across the hour test session reflects the simple effects of satiation. The fact that the $32 \%$ solution resulted in lower initial response output and, together with the $16 \%$ solution, more responding in the latter portion of the session is perhaps a result of the motivational state used. Thirsty rats, when exposed to sucrose will initially be more highly motivated to reduce the thirst drive which necessarily means that lower concentrations of sucrose would yield higher instrumental response outputs. After satiation for water has occurred the sugar acquires a greater significance and higher concentrations lead to greater responding. Thus the results obtained in experiments using thirsty rats and sucrose rewards must take into account the duration of exposure across a day's trials to the reinforcing solution.

If limited exposures are permitted then thirsty rats produce less responses for 4,8 , and $16 \%$ concentrations than for $32 \%$ concentrations. These data on initial 15-min exposure replicate in part the results of Tombaugh \& Marx (1965) and together with the results of Guttman (1953) lend support to the hypothesis that sucrose solutions have differential reinforcing properties for hungry and thirsty rats. The slower running speeds of a water-deprived group of rats for rewards of 400 licks of a $50 \%$ sucrose solution as compared to 400 licks of a $5 \%$ solution (Ison \& Rosen, 1965) is also consonant with the present suggestion.

\section{REFERENCES}

GUTTMAN, N. Operant conditioning, extinction and periodic reinforcement in relation to concentration of sucrose used as reinforcing agent. Journal of Experimental Psychology, 1953, 46, 213-224.

ISON, J. R., \& ROSEN, A. J. On changes in incentive: Some new findings and theoretical speculation. Paper presented at the meeting of the Psy chonomic Society, Chicago, October, 1965.

TOMBAUGH, T. N., \& MARX, M. H. Effects of ordered and constant sucrose concentrations on nonreinforced performance. Journal of Experimental Psychology, 1965, 69, 630-636. 